Europe and the U.S.A., led to the formation of an International Committee at a meeting of the International Society of Medical Hydrology in Paris in 1927. From this Committee sprang the Ligue, though interest in the subject had first been awakened at the International Congress on Physical Treatment in 1913, when Dr. van Breemen of Amsterdam initiated the idea of an institute for scientific research into the rheumatic diseases. The first world war postponed further development at that time, but the idea was revived, thanks to the energy and devotion of Dr. van Breemen, and though its progress was interrupted again by the second world war the Ligue has now grown into a world-wide movement. Of these developments the Yearbook, which is in itself a tribute to the vision and enthusiasm of the founders of the Ligue, gives an interesting historical account, with forewords by eminent physicians in English, French, and Spanish. The rules and constitutions of the Ligue Internationale, the Ligue Européenne, and the Pan-American League are set out in these three languages with lists of the officials and members of the numerous branches and affiliated societies all over the world.

Copies may be ordered through Dr. W. S. Tegner, the Secretary-treasurer, London Hospital, London, E.1. Other communications regarding this publication should be addressed to Mr. Ove de Bornemann, Støre Strandstraede 19, Copenhagen, Denmark.

\title{
CORRESPONDENCE
}

\section{IRON THERAPY IN THE ANAEMIA OF RHEUMATOID ARTHRITIS}

To the Editors, Annals of the Rheumatic Diseases.

20.2.51.

DEAR SIRS,-In your last number, the interesting paper by Dr. D. N. Ross on "Iron Therapy in the Anaemia of Rheumatoid Arthritis" states that the "results in Table II show the statistically significant superiority of the administration of iron by the intravenous route . . .". As neither standard deviations nor probabilities are furnished, the statement is untrue, and it is left in doubt whether, in fact, tests of probability have been applied or whether the term " statistically significant " is used (as so often happens nowadays) as an incantation to ward off criticism. I hope the author will be able to supply from his data this calculation, and thus complete the paper.

Yours faithfully,

E. G. L. Bywaters, F.R.C.P.

Canadian Red Cross Memorial Hospital, Taplow, Maidenhead, Berks. 